\title{
Mortality in Fibromyalgia: A Study of 8,186 Patients Over Thirty-Five Years
}

\author{
FREDERICK WOLFE, ${ }^{1}$ AFTON L. HASSETT, ${ }^{2}$ BRIAN WALITT, ${ }^{3}$ AND KALEB MICHAUD ${ }^{4}$
}

Objective. To determine if mortality is increased among patients diagnosed as having fibromyalgia.

Methods. We studied 8,186 fibromyalgia patients seen between 1974 and 2009 in 3 settings: all fibromyalgia patients in a clinical practice, patients participating in the US National Data Bank for Rheumatic Diseases (NDB), and patients invited to participate in the NDB who refused participation. Internal controls included 10,087 patients with osteoarthritis. Deaths were determined by multiple source communication, and all patients were also screened in the US National Death Index (NDI). We calculated standardized mortality ratios (SMRs) based on age- and sex-stratified US population data, after adjustment for NDI nonresponse.

Results. There were 539 deaths, and the overall SMR was 0.90 (95\% confidence interval [95\% CI] 0.61-1.26). Among 1,665 clinic patients, the SMR was 0.92 (95\% CI 0.81-1.05). Sensitivity analyses varying the rate of NDI nonidentification did not alter the nonassociation. Adjusted for age and sex, the hazard ratio for fibromyalgia compared with osteoarthritis was 1.05 (95\% CI 0.94-1.17). The standardized mortality odds ratio (OR) compared with the US general population was increased for suicide (OR 3.31, 95\% CI 2.15-5.11) and for accidental deaths (OR 1.45, 95\% CI 1.02- 2.06), but not for malignancy.

Conclusion. Mortality does not appear to be increased in patients diagnosed with fibromyalgia, but the risk of death from suicide and accidents was increased.

\section{INTRODUCTION}

Fibromyalgia arose as a common clinical diagnosis around 1980 (1-3), and the American College of Rheumatology (ACR) provided classification criteria for the disorder in 1990 (4). Most evidence suggests that fibromyalgia is not a discrete medical disorder, but rather that it represents the end of a continuum of polysymptomatic distress $(5,6)$, though some would demur (7). The ACR 1990 criteria required that chronic widespread pain be present for a fibromyalgia diagnosis, and widespread pain, therefore, lies on the pathway to fibromyalgia. One population-based

${ }^{1}$ Frederick Wolfe, MD: National Data Bank for Rheumatic Diseases and University of Kansas School of Medicine, Wichita; ${ }^{2}$ Afton L. Hassett, PsyD: University of Michigan Medical School, Ann Arbor; ${ }^{3}$ Brian Walitt, MD, MPH: Georgetown University and Washington Hospital Center, Washington, DC; ${ }^{4}$ Kaleb Michaud, PhD: University of Nebraska Medical Center, Omaha, and National Data Bank for Rheumatic Diseases, Wichita, Kansas.

Dr. Hassett has received consultant fees and speaking fees (less than \$10,000 each) from Forest Pharmaceuticals and Jazz Pharmaceuticals.

Address correspondence to Frederick Wolfe, MD, National Data Bank for Rheumatic Diseases, 1035 North Emporia, Suite 288, Wichita, KS 67214. E-mail: fwolfe@arthritisresearch.org.

Submitted for publication March 26, 2010; accepted in revised form July $7,2010$. epidemiologic study found that chronic widespread pain was associated with the risk of increased mortality (8), although that finding has not been confirmed in another large population-based study (9). Chronic severe pain, including pain caused by cancer and angina, has been shown to be associated with increased mortality (10).

There are several reasons why mortality might be increased in fibromyalgia. Patients with the disorder are substantial users of analgesics and antidepressants (11), have many somatic symptom disorders (12), and have high rates of depression $(13,14)$. It seems possible that depression, sociodemographic characteristics, or iatrogenesis could lead to increased mortality. The risk could also be increased if fibromyalgia is a representation of more extensive widespread pain or more severe symptoms.

We hypothesized that fibromyalgia not associated with another important illness ("primary" fibromyalgia) will have no association or only a slight association with mortality and that fibromyalgia that occurs in the presence of another important illness (secondary or concomitant fibromyalgia) will have such an association. The latter type of fibromyalgia has been confirmed by increased rates of fibromyalgia occurring in patients with other medical disorders (15).

The current study of 8,186 fibromyalgia patients with primary fibromyalgia attempts to answer the question of whether primary fibromyalgia is associated with an in- 
creased risk of mortality. The best answer to such a question should come from population-based data. Although there have been population surveys to determine fibromyalgia prevalence using the ACR 1990 criteria, the number of cases identified are too few to determine subsequent mortality risk, with the result that there are no populationbased mortality studies of fibromyalgia. An earlier clinical study from Denmark did not find mortality increased in fibromyalgia (16).

In the current report, we use clinical patients to make inferences about mortality using standardized mortality ratios (SMRs). This can be an uncertain process if clinic patients differ systematically from persons in the general population, differences that could occur if the studied fibromyalgia patients have more or less severe fibromyalgia or have different sociodemographic characteristics than persons in the general population. To help interpret fibromyalgia data, we used 10,087 internal osteoarthritis (OA) controls to determine if the risk of mortality differs between the groups. We used OA patients because their risk of mortality is close to that of the general population, or only slightly increased (17), and because they have pain problems as well. Patients with OA have been used as controls for fibromyalgia criteria studies $(4,18)$.

\section{MATERIALS AND METHODS}

Three related data sets (sources) were used in this study. Of the 8,186 patients with fibromyalgia, 1,115 came from the community clinical practice of the senior author (FW) and were not enrolled in the National Data Bank for Rheumatic Diseases (NDB) longitudinal study of rheumatic disease outcomes. This group was called the Wichita nonparticipant group. There were 3,589 patients referred to the NDB by US rheumatologists who elected not to participate in the NDB (NDB nonparticipants), and 3,482 who became participants in the NDB. Participation required the completion of detailed semiannual questionnaires. The reasons for nonparticipation are not known; nonparticipation is discussed further in the Discussion section. Of the NDB participants, 550 came from the senior author's practice (FW) and represented all fibromyalgia patients seen in his clinic during the years 1974 to 2004 . They were diagnosed using criteria in effect at the time of entry $(4,19,20)$. Of the 1,115 patients seen by the senior author, 476 were first seen prior to 1990, the year of the publication of the ACR 1990 classification criteria (4). The NDB was established and began enrolling patients in 1998. Diagnoses for nonWichita patients were made by referring rheumatologists. We also analyzed data from the 3 sources for patients with OA. We used these patients to provide internal controls for mortality analyses. Of the 10,087 OA patients, 4,073 were NDB non-enrollees, 4,550 were NDB enrollees, and 1,464 were Wichita non-NDB enrollees. All Wichita OA patients had OA of the knee or hip. Of the NDB OA patients, 3,402 had OA of the knee or hip; the remainder carried a diagnosis of OA without further specification. The overall mean \pm SD age of the OA patients was $64.6 \pm 12.2$ years, and $77.9 \%$ were women.

The NDB obtains participants primarily by rheumatolo- gist referral, and in these cases the rheumatologist provides the diagnosis. A small minority of participants enroll from other sources, including self-referral, after obtaining information from physicians, societies, and web sites. In such cases the NDB obtains diagnostic confirmation from the participants' physicians. There were 19 Canadian patients with fibromyalgia in the NDB. These patients were not included in the study because we used only US death source information.

Study variables. The NDB surveys patients by detailed, 28-page postal or internet questionnaires at 6-month intervals (21). Although not used for entry criteria for patients in this study, 4 study variables were related to diagnostic classification for NDB patients and were used in the analysis of NDB data: the fibromyalgianess scale $(22,23)$, the Widespread Pain Index (WPI) $(18,24)$, widespread pain (from the ACR 1990 criteria definition) (4), and fibromyalgia diagnosis modified (23) from the ACR 2010 diagnostic criteria (18). To be clear, the modified diagnostic criteria and the fibromyalgianess scale are not part of the ACR 2010 criteria, although the modifications to the $2010 \mathrm{cri}-$ teria that allow survey research were made by ACR 2010 criteria authors. The WPI is a count of the number of 19 nonarticular regions noted to be painful. In the NDB surveys these data are obtained by self-report. The presence of widespread pain is determined from the examination of specific painful regions, and widespread pain is said to be positive if there is pain above and below the waist, on the left and right side of the body, and in the axial skeletal region (4). Patients are considered to be fibromyalgia criteria-positive if they satisfy modified ACR 2010 preliminary diagnostic criteria. In a previous study, we modified these criteria so that they could be used for survey research (23). However, some of the 2010 criteria variables were not available prior to 2009. Therefore, we used the symptom intensity scale (SI) (25) to derive diagnostic criteria and fibromyalgianess scales in this study. The fibromyalgianess scale is similar to the previously described SI scale (24). Although the SI scale combines a visual analog scale (VAS) fatigue scale with the WPI, and the fibromyalgianess scale combines the WPI with a 4-item symptom severity scale (not available in this study), the 2 scales are effectively the same in terms of performance. When the SI scale is transformed to the same scale length of the fibromyalgianess scale $(0-31)$, the Pearson's correlation coefficient of the scales is 0.963 and Lin's concordance coefficient is 0.956 (18). This indicates that the scales have almost the exact same performance characteristics, i.e., "The scale captures well the essential content of fibromyalgia or what we have called 'fibromyalgianess"' (22). The modification of the 2010 criteria for diagnosis with data prior to 2009 in the NDB was: (WPI $\geq 7$ and VAS fatigue $>5$ ) or ([WPI $\geq 7$ and VAS fatigue $\leq 5$ ] and a count of somatic symptoms $\geq 13$ ).

Additional clinical variables included the Health Assessment Questionnaire (HAQ) (26), the physical and mental component summary scores from the Short Form 36 health survey $(27,28)$, and VAS scales for pain, fatigue, and patient global severity. 
Although we collected data on disease duration, there is no agreed upon definition of disease duration in fibromyalgia, and we do not know how individual study physicians or patients defined onset. It is possible that the disorder might be defined by the onset of many somatic symptoms or the first regional or local pain problem, rather than the onset of generalized pain or fibromyalgia diagnosis. We present duration data in relation to suicide data because it may offer some explanatory information, but we urge extreme caution in relying on or extrapolating from these data (caveat lector).

Death data. The NDB obtains death information, including cause of death, from families and physicians. Followup for mortality began at entry into the cohort. In addition, all patients, whether they are known to be alive or not, are submitted annually to the US National Death Index (NDI), since the NDI provides cause of death information $(29,30)$. The NDI receives all reports of deaths from the individual states, and represents the repository of all individual death information in the US. The NDI reports lag behind actual deaths. To account for this, we censored patients whose death status was not known as of December 31, 2007. The sensitivity of the NDI death ascertainment depends upon the availability of the social security number (SSN) identifier (31). The NDI identified $97 \%$ of deaths over a 6 -year period when the SSN was available and $87 \%$ when not available in one study, and this proportion fell to $85 \%$ in women without SSNs (32). The SSN and non-SSN rates were $92 \%$ and $87 \%$, respectively, in another study of men (33). For privacy reasons, full SSNs were not available to the NDB. The last 4 digits of the SSN were collected in recent years in the NDB; overall, $25.2 \%$ of fibromyalgia patients in this study had last 4-digit SSN data available.

Statistical analysis. Because the literature cited in the paragraph above suggested underestimation of deaths derived from the NDI for NDB participants and NDB nonparticipants, we used the information from the paragraph above and our experience with NDB data to estimate an under-identification rate of $\sim 12 \%$. We then used a random number generator to randomly change $12 \%$ of patients classified as being alive to being dead to account for this potential misclassification. We did not increase the number of deaths for the Wichita patients because internal studies of Wichita mortality over a 20-year period indicated $100 \%$ death capture. We used the determined deaths plus the randomly added deaths as the observed deaths in this report. In the analyses described below, we performed sensitivity analyses by increasing randomly created deaths to $20 \%$ and then measured the effect on SMRs. To determine SMRs from survival analyses, we used the Stata strate (Stata) procedure and age-, sex-, and calendar-stratified reference mortality rates from the US white general population $(34,35)$. SMRs that included multiple groups used jackknife confidence intervals clustered on the groups. Cause-specific mortality data were obtained from National Vital Statistics Reports for 2006 (36). We calculated the standardized mortality odds ratio (OR) based on the age- and sex-stratified number of deaths from underly-
Table 1. Characteristics of NDB participants with fibromyalgia*

\begin{tabular}{|c|c|}
\hline Variable & Mean \pm SD \\
\hline \multicolumn{2}{|l|}{ Age, yearst } \\
\hline $\begin{array}{l}\text { NDB non-enrollees }(\mathrm{n}=3,589 \text {, } \\
\text { 93.1\% women) }\end{array}$ & $50.4 \pm 12.6$ \\
\hline $\begin{array}{l}\text { NDB enrollees ( } \mathrm{n}=3,482,95.4 \% \\
\text { women) }\end{array}$ & $51.7 \pm 11.9$ \\
\hline $\begin{array}{l}\text { Wichita non-NDB (n = 1,115, } \\
\text { 91.3\% women) }\end{array}$ & $47.0 \pm 12.9$ \\
\hline $\begin{array}{l}\text { All sources (n = 8,186, 93.9\% } \\
\text { women) }\end{array}$ & $50.5 \pm 12.4$ \\
\hline High school graduate, \% & 93.7 \\
\hline College graduate, \% & 29.5 \\
\hline Non-Hispanic white, \% & 92.8 \\
\hline Medical insurance, \% & 93.7 \\
\hline Married, \% & 68.4 \\
\hline \multicolumn{2}{|l|}{ Smoking, \% } \\
\hline Never & 53.3 \\
\hline Past & 29.8 \\
\hline Current & 16.9 \\
\hline Body mass index, $\mathrm{kg} / \mathrm{m}^{2}$ & $30.1 \pm 7.6$ \\
\hline HAQ score $(0-3)$ & $1.1 \pm 0.6$ \\
\hline Pain score $(0-10)$ & $6.4 \pm 2.3$ \\
\hline Global severity score (0-10) & $5.5 \pm 2.4$ \\
\hline Fatigue score $(0-10)$ & $7.0 \pm 2.5$ \\
\hline $\begin{array}{l}\text { Physical component summary } \\
\text { score }\end{array}$ & $31.8 \pm 8.8$ \\
\hline Mental component summary score & $41.6 \pm 12.2$ \\
\hline $\begin{array}{l}\text { Fibromyalgia diagnosis by modified } \\
\text { ACR } 2010 \text { criteria, } \%\end{array}$ & 67.4 \\
\hline Widespread pain, \% & 81.4 \\
\hline NDB fibromyalgianess scale (0-31) & $19.1 \pm 7.3$ \\
\hline \multicolumn{2}{|c|}{$\begin{array}{l}\text { * Medical insurance, marital status, smoking status, body mass } \\
\text { index, HAQ score, pain, physical and mental component summary } \\
\text { scores, modified ACR criteria diagnosis, and fibromyalgia diagnosis } \\
\text { were only available in NDB participants. Other demographics are } \\
\text { available in the NDB nonparticipant and the Wichita cohorts. } \\
\text { NDB = National Data Bank for Rheumatic Diseases; HAQ = Health } \\
\text { Assessment Questionnaire; ACR = American College of Rheuma- } \\
\text { tology. } \\
+ \text { Represents age at study start. }\end{array}$} \\
\hline
\end{tabular}

ing specific causes in the general population and in study subjects (without the random 12\% increase in deaths).

Comparison of the risk of mortality for fibromyalgia versus OA utilized Cox regression clustered, where appropriate, on source groups. Predictors of mortality were analyzed using Cox regression adjusted for age and sex. All analyses were performed using Stata, version 11.0 (Stata) (34). Statistical significance was set at 0.05 , and all tests were 2-tailed.

\section{RESULTS}

There were 8,186 patients with fibromyalgia distributed across the 3 source groups (Table 1), including a total of 1,665 from the Wichita clinical practice. The mean \pm SD time in the study, from entry to death or censoring, was $7.3 \pm 5.9$ years (range 0.1-31 years) or through 60,413 patient-years of followup. NDB fibromyalgia patients had high levels of pain (6.4), fatigue (7.0), and global severity (5.5) at entry. Widespread pain was identified in $81.4 \%$ of 


\begin{tabular}{|c|c|c|c|c|c|}
\hline Group & Patients, no. & Deaths & Expected deaths & SMR & $\mathbf{9 5} \% \mathrm{CI}$ \\
\hline NDB non-enrollees & 3,589 & 186 & 173.52 & 1.07 & $0.92-1.24$ \\
\hline NDB enrollees & 3,482 & 187 & 277.79 & 0.67 & $0.58-0.78$ \\
\hline Wichita non-NDB & 1,115 & 166 & 149.40 & 1.11 & $0.95-1.29$ \\
\hline All patientst & 8,186 & 539 & 600.71 & 0.90 & $0.61-1.26$ \\
\hline Wichita NDB enrollees and non-enrollees & 1,665 & 221 & 239.56 & 0.92 & $0.81-1.05$ \\
\hline NDB enrollees, ACR 2010 criteria positive & 2,265 & 122 & 142.77 & 0.85 & $0.72-1.02$ \\
\hline
\end{tabular}

patients; $67.6 \%$ of patients satisfied modified survey diagnostic criteria.

Risk of mortality by source group. Fibromyalgia patients differed as to their risk of mortality according to the source group. After adjustment for age and sex, the risk of mortality for NDB non-enrollees was hazard ratio (HR) 1.56 (95\% confidence interval [95\% CI] 1.27-2.91) and HR 1.77 (95\% CI 1.42-2.19) for Wichita non-NDB patients compared with NDB enrollees.

SMR. Source group differences translated into differences in the SMR when fibromyalgia patients were compared with the US population, stratified by age and sex (Table 2). Wichita non-NDB patients had the largest SMR at 1.11 (95\% CI 0.95-1.29), and NDB patients had the smallest SMR at 0.67 (95\% CI 0.58-0.78). When the groups were combined, the overall SMR was 0.90 (95\% CI 0.61-1.26). When NDB patients who satisfied the survey modification of the ACR 2010 criteria were studied, their SMR was 0.85 (95\% CI 0.72-1.02). We also determined the SMR of all Wichita patients regardless of whether they were NDB participants or not. For this group the SMR was 0.92 (95\% CI 0.81-1.05).

In a sensitivity analysis, we assumed that the NDI underidentification of deaths was $20 \%$, instead of the $12 \%$ assumption used for all other analyses, and we randomly increased the observed deaths by $20 \%$. We then analyzed the 3 source groups and found that the overall SMR was 0.96 (95\% CI 0.65-1.38). Therefore, the result of all of the study analyses under 2 assumptions suggests no increase in mortality in patients with fibromyalgia.

Comparison with OA patients. We also used internal controls to assess the risk of mortality in fibromyalgia by comparing fibromyalgia patients with those with OA in Cox regression analyses adjusted for age and sex. As shown in Table 3, there was no increased risk associated with fibromyalgia overall (HR 1.05, 95\% CI 0.94-1.17), nor when the analyses were restricted to OA patients with known OA of the hip or knee.

Cause-specific mortality. Table 4 shows major causes of death in the study patients compared with the US population, after stratification for age and sex. The standardized mortality OR was increased for suicide (OR 3.31, 95\% CI
2.15-5.11), accidental deaths (OR 1.45, 95\% CI 1.02-2.06), septicemia (OR 2.49, 95\% CI 1.61-3.68), and influenza and pneumonia (OR 1.69, 95\% CI 1.12-2.57), but not for malignancy (OR 0.95, 95\% CI 0.76-1.18). Figure 1 shows that death from suicide occurs soon after entry into the study in contradistinction to other death causes. The mean \pm SD age of the 15 fibromyalgia patients who died from suicide was $46.5 \pm 11.4$ years at entry into the study compared with $60.2 \pm 13.0$ years for those who died of other causes, and their disease duration was 16.4 years $(\mathrm{n}=11)$ compared with mean \pm SD $12.5 \pm 12.1$ years for those who died of other causes.

Predictors of mortality in the NDB fibromyalgia population. Table 5 displays a series of Cox regression analyses in which each analysis was adjusted for age and sex. Fibromyalgianess and satisfying the survey-modified ACR 2010 criteria at entry, but not widespread pain, was associated with an increased risk of mortality. Education level and sex were not associated with risk of mortality, but all other demographic and clinical variables contributed to the risk.

\section{DISCUSSION}

The results of this study suggest that mortality is not increased in fibromyalgia. Within the NDB participant

Table 3. Risk of mortality in fibromyalgia compared with $\mathrm{OA}^{*}$

\begin{tabular}{|c|c|c|c|}
\hline Source & HR & $P>\mathrm{z}$ & 95\% CI \\
\hline \multicolumn{4}{|l|}{ All OA group } \\
\hline All† & 1.05 & 0.410 & $0.94-1.17$ \\
\hline NDB non-enrollees & 1.15 & 0.162 & $0.94-1.40$ \\
\hline NDB enrollees & 0.98 & 0.788 & $0.82-1.17$ \\
\hline Wichita non-enrollees & 1.04 & 0.665 & $0.86-1.27$ \\
\hline \multicolumn{4}{|l|}{ Known OA of hip/knee } \\
\hline NDB non-enrollees & 1.03 & 0.788 & $0.78-1.38$ \\
\hline NDB enrollees & 0.90 & 0.298 & $0.73-1.10$ \\
\hline Wichita non-enrollees & 1.04 & 0.665 & $0.86-1.27$ \\
\hline \multicolumn{4}{|c|}{$\begin{array}{l}\text { * Adjusted for age and sex. OA = osteoarthritis; } \mathrm{HR}=\text { hazard ratio; } \\
95 \% \mathrm{CI}=95 \% \text { confidence interval; NDB }=\text { National Data Bank of } \\
\text { Rheumatic Diseases. } \\
\text { † Clustered on fibromyalgia groups. }\end{array}$} \\
\hline
\end{tabular}


Table 4. Percent of deaths by leading causes for all fibromyalgia patients*

\begin{tabular}{|lcrc|}
\hline \multicolumn{1}{|c}{ Cause of death } & Patients, \% & US population, \% & SMR (95\% CI) \\
\hline Heart diseases & 22.9 & 26.0 & $0.84(0.68-1.04)$ \\
Malignant neoplasms & 22.2 & 23.1 & $0.95(0.76-1.18)$ \\
Accidents (unintentional injuries) & 7.1 & 5.0 & $1.45(1.02-2.06)$ \\
Chronic lower respiratory diseases & 5.6 & 5.1 & $1.09(0.74-1.62)$ \\
Influenza and pneumonia & 5.0 & 2.3 & $1.69(1.12-2.57)$ \\
Septicemia & 4.5 & 1.4 & $2.49(1.61-3.68)$ \\
Intentional self-harm (suicide) & 4.4 & 1.4 & $3.31(2.15-5.11)$ \\
Cerebrovascular diseases & 4.2 & 1.9 & $0.75(0.48-1.17)$ \\
Nephritis/nephrotic syndrome/nephrosis & 2.2 & 3.0 & $0.93(0.50-1.72)$ \\
Alzheimer's disease & 1.7 & 1.0 & $0.57(0.29-1.13)$ \\
Essential hypertension/hypertensive renal disease & 1.1 & 1.1 & $0.95(0.40-2.23)$ \\
Chronic liver disease and cirrhosis & 0.7 & 0.8 & $0.47(0.16-1.38)$ \\
Parkinson's disease & 0.2 & 0.8 & $0.22(0.00-1.23)$ \\
Assault (homicide) & 0.3 & $0.26(0.00-1.51)$ \\
\hline
\end{tabular}

* Includes National Data Bank of Rheumatic Diseases participants and nonparticipants and Wichita nonparticipants. SMR = standardized mortality ratio; $95 \%$ CI = 95\% confidence interval.

group, however, fibromyalgia patients satisfying modified ACR 2010 criteria at entry had an increased risk of death (HR 1.62, 95\% CI 1.19-2.21). Recent studies have shown that at least $25 \%$ of patients carrying a diagnosis of fibromyalgia do not satisfy ACR 1990 or 2010 criteria, or survey-modified 2010 criteria $(4,18,23)$. In fact, $32.6 \%$ of patients in the NDB participant group did not meet the survey-modified 2010 criteria. This occurs primarily because patients improve and/or symptoms lessen. So when fibromyalgia is being considered with respect to mortality in this study, we are de facto including all patients who have been diagnosed with fibromyalgia and are generally considered to be "fibromyalgia patients."

The risk of mortality was increased in NDB non-enrollees (HR 1.56, 95\% CI 1.27-2.91), and Wichita non-enrollees (HR 1.77, 95\% CI 1.42-2.19) compared with NDB enrollees. A wide variety of studies have shown lower mortality rates in voluntary participants than nonparticipants (37-39). As an example, "Out of 10,000 men invited to a screening examination ... in Goteborg, Sweden, 25\% did not come to the examination," "The annual mortality among the nonparticipants was about twice that of the

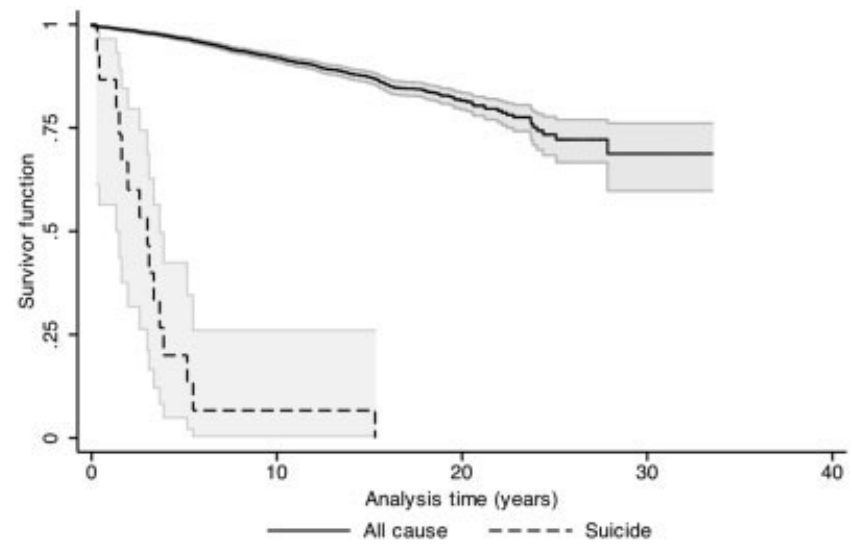

Figure 1. Kaplan-Meier survival estimates comparing death by suicide with all other causes of death in patients with fibromyalgia. participants during the entire follow-up period of 11.8 years" (40). In the current study, mortality was less in NDB participants compared with NDB nonparticipants, and was consistent with the studies cited above (37-40). The Wichita nonparticipant group can be considered equivalent to a mixture of nonparticipants and participants, since $85 \%$ of this group of clinic patients were evaluated before the existence of the NDB and could not have been NDB participants. To account for the differences among the 3 groups, we calculated the overall SMR, after clustering on group. The combined SMR was 0.90 (95\% CI 0.61-1.26). Although the NDB enrollees reduced the overall SMR, none of the groups had a significant mortality increase. We further studied mortality in the Wichita clinic patients by including the Wichita nonparticipants with Wichita patients who became part of the NDB. The SMR for this combined group was 0.92 (95\% CI 0.81-1.05).

There is also support for the finding of no increase in mortality by comparing fibromyalgia mortality with OA mortality. In all Wichita patients, the HR for mortality, adjusted for age and sex, was 1.13 (95\% CI 0.96-1.33), and in all patients in the study the HR was 1.02 (95\% CI 0.97-1.07). There is some controversy as to whether mortality is increased in OA. In a review, Hochberg concludes, "Overall, there was moderate evidence of increased mortality among persons with osteoarthritis compared with the general population" (17). However, as Hochberg points out, this conclusion is dependent on how OA is defined. In a study by Watson and colleagues that used the UK General Practice Research Database in 61,517 men and 101,757 women with a clinical diagnosis of OA, the rates of ageadjusted all-cause mortality per 1,000 patient-years were 19.5 and 15.9 in men and women with OA, respectively, and 20.6 and 17.3 in men and women with no arthritis, respectively (41). The authors concluded that the rates in patients with OA and those with no arthritis were essentially the same. The major limitation of this study was that the diagnosis of OA was recorded by general practitioners using unknown criteria. It seems possible that the mortal- 


\begin{tabular}{|c|c|c|c|c|c|}
\hline & HR & SE & $\mathbf{z}$ & $\boldsymbol{P}$ & $\mathbf{9 5} \% \mathrm{CI}$ \\
\hline Fibromyalgianess & 1.05 & 0.01 & 4.21 & 0.000 & $1.02-1.07$ \\
\hline Fibromyalgia criteria (positive) & 1.62 & 0.26 & 3.03 & 0.002 & $1.19-2.21$ \\
\hline Widespread pain (positive) & 1.28 & 0.23 & 1.35 & 0.178 & $0.90-1.82$ \\
\hline Age, years & 1.05 & 0.01 & 8.88 & 0.000 & $1.05-1.07$ \\
\hline Sex, male & 1.01 & 0.33 & 0.04 & 0.967 & $0.53-1.92$ \\
\hline High school graduate & 0.82 & 0.20 & -0.82 & 0.412 & $0.51-1.31$ \\
\hline College graduate & 1.02 & 0.18 & 0.12 & 0.908 & $0.72-1.44$ \\
\hline Married vs. divorced/separated & 0.73 & 0.11 & -2.00 & 0.045 & $0.54-0.99$ \\
\hline Married vs. all & 0.63 & 0.15 & -1.99 & 0.047 & $0.39-0.99$ \\
\hline Body mass index $>29 \mathrm{~kg} / \mathrm{m}^{2}$ & 1.54 & 0.23 & 2.83 & 0.005 & $1.14-2.07$ \\
\hline HAQ (0-3) & 1.99 & 0.24 & 5.79 & 0.000 & $1.58-2.52$ \\
\hline Fatigue $(0-10)$ & 1.09 & 0.03 & 2.81 & 0.005 & $1.03-1.16$ \\
\hline Pain $(0-10)$ & 1.17 & 0.05 & 3.59 & 0.000 & $1.08-1.28$ \\
\hline Mood $(0-10)$ & 1.07 & 0.05 & 1.62 & 0.105 & $0.99-1.16$ \\
\hline Physical component score & 0.95 & 0.01 & -5.26 & 0.000 & $0.93-0.97$ \\
\hline Mental component score & 0.99 & 0.01 & -1.94 & 0.052 & $0.98-1.00$ \\
\hline \multicolumn{6}{|l|}{ Smoking vs. never } \\
\hline Past & 1.42 & 0.24 & 2.10 & 0.036 & $1.02-1.96$ \\
\hline Current & 2.63 & 0.55 & 4.61 & 0.000 & $1.74-3.97$ \\
\hline
\end{tabular}

ity rate might have been increased had validated criteria been used.

In determining SMRs, we ran into the problem of underestimating mortality in determining deaths using the NDI. For reasons of privacy and patient acceptability, the NDB did not have full SSNs. However, $\sim 25 \%$ of patients provided the last 4 digits of the SSN, and this enabled us to match to full SSNs in the NDI in this group of patients. As indicated in the Materials and Methods section (31-33), the sensitivity of the NDI for identification of deaths is $\sim 85 \%$ for women in the absence of SSNs. To compensate for this deficiency, we randomly increased the number of deaths by $12 \%$ among NDB enrollees and NDB nonparticipants. We did not increase the deaths for Wichita nonenrollees because internal studies indicated 100\% death capture among the Wichita patients. Since the interpretation of the SMR depends on the level of additional deaths added in the NDB section of the study, we performed a sensitivity analysis in which we increased deaths by $20 \%$. In this analysis we did not see an overall increase in SMR compared with the US general population. Although these data have a degree of uncertainty, we found no evidence to suggest an increase in mortality among fibromyalgia patients.

There are few data regarding mortality in fibromyalgia. Mäkelä and Heliövaara reported no increase in mortality in a Finnish population study (42). However, they used an ad hoc definition of fibromyalgia that is inconsistent with all criteria definitions. Dreyer et al reported, in an abstract/ presentation in 2004, on 1,217 confirmed cases of fibromyalgia in Danish women seen between 1984 and 1999 (16). The SMR was not increased and there was no increase in mortality from cancer. In a 2010 update of that study (43), the authors confirmed the cancer findings and noted additionally an increased risk of suicide in fibromyalgia.

Andersson studied 214 persons with widespread ( $\mathrm{n}=$
70) or local (neck-shoulder) pain or without chronic pain recruited from the general population and reported increased mortality in those with widespread pain after 12 years followup (44). Macfarlane and colleagues found an increase in mortality in a population study of persons with widespread pain in the UK (8), and this increase has been attributed to an increase in cancer cases $(45,46)$. However, a subsequent study has not confirmed the association of widespread pain and mortality (9).

In agreement with the Danish report and in contradistinction to the reports of the increase in cancer in patients with widespread pain $(45,46)$, we did not find increased cancer mortality among fibromyalgia deaths (Table 4), and we did find increases in suicide and accidental deaths. Further, almost $20 \%$ of deaths attributed to accidents may actually be suicides (47), so the OR that we found for suicide of 3.31 (95\% CI 2.15-5.11) might be closer to 4.0 if accidents were misattributed. We also found an increase in deaths from pneumonia/influenza and septicemia, a result for which we have no medical explanation, and a result that should be accepted with caution and will require confirmation.

There is no clear-cut interpretation of the finding that death from suicide is an early phenomenon (Figure 1). One possibility is that the severity of symptoms led to physician visits and consequent study entry, and the severity subsequently lessened. This would suggest an association of health-seeking behavior and psychological problems, such as depression, in some patients with fibromyalgia. The relationship between suicide and antidepressant therapy is tenuous (48), and we did not have sufficient data to evaluate that possibility. Our data concerning suicide should not be interpreted to suggest that fibromyalgia symptoms cause suicide, since our data are cross-sectional and associative, not causative.

The association of fibromyalgia diagnosis based on the 
2010 ACR criteria and on fibromyalgianess suggests that the extent of widespread pain (beyond satisfying the widespread pain criterion) and its accompanying severity may be the prime determinant of increased mortality within the widespread pain group. NDB participants satisfying the modified 2010 criteria had an increased SMR (0.85) compared with the overall NDB participant SMR (0.67).

Practically speaking, fibromyalgia has been a clinical diagnosis rather than a disorder that can be studied in the general population. This occurs because the prevalence of fibromyalgia is low and its identification requires a physical examination, according to ACR 1990 criteria. It may well be that the actual SMR would have been greater had patients identified in population surveys been studied. But there are no such patients. The patients in our study may have had better socioeconomic status, since almost all (94\%) had medical insurance and all received care from specialists rather than general physicians, which may be a measure of social class and access to care. Factors such as these have been shown to be associated with increased survival $(49,50)$.

In summary, the overall SMR in patients with fibromyalgia was 0.90 (95\% CI 0.61-1.26). Among 1,665 clinic patients the SMR was 0.92 (95\% CI 0.81-1.05). Sensitivity analyses varying the rate of NDI nonidentification did not alter the nonassociation. Adjusted for age and sex, the HR for fibromyalgia compared with OA was 1.05 (95\% CI 0.94-1.17). However, the standardized mortality OR was increased for suicide (OR 3.31, 95\% CI 2.15-5.11) and for accidental deaths (OR 1.45, 95\% CI 1.02-2.06), but not for malignancy.

\section{AUTHOR CONTRIBUTIONS}

All authors were involved in drafting the article or revising it critically for important intellectual content, and all authors approved the final version to be submitted for publication. Dr. Wolfe had full access to all of the data in the study and takes responsibility for the integrity of the data and the accuracy of the data analysis.

Study conception and design. Wolfe, Hassett, Walitt.

Acquisition of data. Wolfe, Michaud.

Analysis and interpretation of data. Wolfe, Hassett, Walitt, Michaud.

\section{REFERENCES}

1. Smythe HA, Moldofsky H. Two contributions to understanding of the "fibrositis" syndrome. Bull Rheum Dis 1977;28: 928-31.

2. Yunus M, Masi AT, Calabro JJ, Miller KA, Feigenbaum SL. Primary fibromyalgia (fibrositis): clinical study of 50 patients with matched normal controls. Semin Arthritis Rheum 1981; 11:151-71.

3. Bennett RM. Fibrositis: misnomer for a common rheumatic disorder. West J Med 1981;134:405-13.

4. Wolfe F, Smythe HA, Yunus MB, Bennett RM, Bombardier C, Goldenberg DL, et al. The American College of Rheumatology 1990 criteria for the classification of fibromyalgia: report of the Multicenter Criteria Committee. Arthritis Rheum 1990;33: $160-72$.

5. Wessely S, Hotopf M. Is fibromyalgia a distinct clinical entity? Historical and epidemiological evidence. Baillieres Best Pract Res Clin Rheumatol 1999;13:427-36.

6. Wolfe F. Fibromyalgia wars. J Rheumatol 2009;36:671-8.
7. Smythe HA. Explaining medically unexplained symptoms: widespread pain. J Rheumatol 2009;36:679-83.

8. Macfarlane GJ, McBeth J, Silman AJ. Widespread body pain and mortality: prospective population based study. BMJ 2001; 323:662-5.

9. Macfarlane GJ, Jones GT, Knekt P, Aromaa A, McBeth J, Mikkelsson $\mathrm{M}$, et al. Is the report of widespread body pain associated with long-term increased mortality? Data from the Mini-Finland Health Survey. Rheumatology (Oxford) 2007; 46:805-7.

10. Torrance N, Elliott AM, Lee AJ, Smith BH. Severe chronic pain is associated with increased 10 year mortality: a cohort record linkage study. Eur J Pain 2010;14:380-6.

11. Goldenberg DL, Burckhardt C, Crofford L. Management of fibromyalgia syndrome. JAMA 2004;292:2388-95.

12. Wolfe F, Hawley DJ. Evidence of disordered symptom appraisal in fibromyalgia: increased rates of reported comorbidity and comorbidity severity. Clin Exp Rheumatol 1999;17: 297-303.

13. Raphael KG, Janal MN, Nayak S, Schwartz JE, Gallagher RM. Familial aggregation of depression in fibromyalgia: a community-based test of alternate hypotheses. Pain 2004;110:44960.

14. Wolfe F, Michaud K, Li T, Katz RS. Chronic conditions and health problems in rheumatic diseases: comparisons with RA, non-inflammatory rheumatic disorders, systemic lupus erythematosus and fibromyalgia. J Rheumatol 2010;37:305-15.

15. Wolfe F, Rasker JJ. Fibromyalgia. In: Firestein GS, Budd RC, Harris ED Jr, McInnes IB, Ruddy S, Sergent JS, editors. Kelley's textbook of rheumatology. 8th ed. Philadelphia: Elsevier; 2008. p. 555-70.

16. Dreyer L, Kendall S, Falk Winther J. Increased suicide, liver disease and cerebrovascular disease mortality in a cohort of Danish patients with fibromyalgia followed for 16 years. Berlin: EULAR; 2004.

17. Hochberg MC. Mortality in osteoarthritis. Clin Exp Rheumatol 2008;26 Suppl 51:S120-4.

18. Wolfe F, Clauw D, Fitzcharles MA, Goldenberg D, Katz RS, Mease P, et al. The American College of Rheumatology preliminary diagnostic criteria for fibromyalgia and measurement of symptom severity. Arthritis Care Res (Hoboken) 2010; 62:600-10.

19. Wolfe F, Cathey MA. Prevalence of primary and secondary fibrositis. J Rheumatol 1983;10:965-8.

20. Wolfe F, Cathey MA. The epidemiology of tender points: a prospective study of 1520 patients. J Rheumatol 1985;12: 1164-8.

21. Wolfe F, Michaud K. A brief introduction to the National Data Bank for Rheumatic Diseases. Clin Exp Rheumatol 2005;23: S168-71.

22. Wolfe F. New American College of Rheumatology criteria for fibromyalgia: a twenty-year journey [editorial]. Arthritis Care Res (Hoboken) 2010;62:583-4.

23. Wolfe F, Clauw D, Fitzcharles MA, Goldenberg D, Hauser W, Katz RS, et al. Fibromyalgia criteria and severity scales for clinical and epidemiological studies: a modification of the ACR preliminary diagnostic criteria for fibromyalgia. J Rheumatol. In press.

24. Wolfe F, Rasker JJ. The Symptom Intensity Scale, fibromyalgia, and the meaning of fibromyalgia-like symptoms. J Rheumatol 2006;33:2291-9.

25. Katz RS, Wolfe F, Michaud K. Fibromyalgia diagnosis: a comparison of clinical, survey, and American College of Rheumatology criteria. Arthritis Rheum 2006;54:169-76.

26. Fries JF, Spitz PW, Kraines RG, Holman HR. Measurement of patient outcome in arthritis. Arthritis Rheum 1980;23:13745 .

27. Ware JE Jr, Sherbourne CD. The MOS 36-item Short-Form health survey (SF-36). I. Conceptual framework and item selection. Med Care 1992;30:473-83.

28. McHorney CA, Ware JE Jr, Lu JF, Sherbourne CD. The MOS 36-item Short-Form Health Survey (SF-36). III. Tests of data quality, scaling assumptions, and reliability across diverse patient groups. Med Care 1994;32:40-66. 
29. Stampfer MJ, Willett WC, Speizer FE, Dysert DC, Lipnick R, Rosner B, et al. Test of the national death index. Am J Epidemiol 1984;19:837-9.

30. Edlavitch SA, Baxter J. Comparability of mortality follow-up before and after the National Death Index. Am J Epidemiol 1988;127:1164-78.

31. Cowper DC, Kubal JD, Maynard C, Hynes DM. A primer and comparative review of major US mortality databases. Ann Epidemiol 2002;12:462-8.

32. Calle EE, Terrell DD. Utility of the National Death Index for ascertainment of mortality among cancer prevention study II participants. Am J Epidemiol 1993;137:235-41.

33. Williams BC, Demitrack LB, Fries BE. The accuracy of the National Death Index when personal identifiers other than Social Security number are used. Am J Public Health 1992; 82:1145-7.

34. Stata C. Stata statistical software: release 11.0. College Station (TX): Stata Corporation; 2009.

35. The Human Mortality Database. 2010. URL: http://www.mortality.org/.

36. Heron M, Hoyert DL, Murphy SL, Xu J, Kochanek KD, Betzaida TV. Deaths: final data for 2006. Nat Vital Stat Rep 2009;57:1-134.

37. Doll R, Hill AB. Mortality in relation to smoking: ten years' observations of British doctors. Br Med J 1964;1:1399-410.

38. Walker M, Shaper AG, Cook DG. Non-participation and mortality in a prospective study of cardiovascular disease. J Epidemiol Community Health 1987;41:295-9.

39. Kauppi M, Sokka T, Hannonen P. Survey nonresponse is associated with increased mortality in patients with rheumatoid arthritis and in a community population. J Rheumatol 2005;32:807-10.

40. Rosengren A, Wilhelmsen L, Berglund G, Elmfeldt D. Nonparticipants in a general population study of men, with special reference to social and alcoholic problems. Acta Med Scand 1987;221:243-51.
41. Watson DJ, Rhodes T, Guess HA. All-cause mortality and vascular events among patients with rheumatoid arthritis, osteoarthritis, or no arthritis in the UK General Practice Research Database. J Rheumatol 2003;30:1196-202.

42. Makela M, Heliovaara M. Prevalence of primary fibromyalgia in the Finnish population. BMJ 1991;303:216-9.

43. Dreyer L, Kendall S, Danneskiold-Samsoe B, Bartels EM, Bliddal H. Mortality in a cohort of Danish patients with fibromyalgia: increased frequency of suicide. Arthritis Rheum 2010;62:3101-8.

44. Andersson HI. The course of non-malignant chronic pain: a 12-year follow-up of a cohort from the general population. Eur J Pain 2004;8:47-53.

45. McBeth J, Symmons DP, Silman AJ, Allison T, Webb R, Brammah T, et al. Musculoskeletal pain is associated with a longterm increased risk of cancer and cardiovascular-related mortality. Rheumatology (Oxford) 2009;48:74-7.

46. McBeth J, Silman AJ, Macfarlane GJ. Association of widespread body pain with an increased risk of cancer and reduced cancer survival: a prospective, population-based study. Arthritis Rheum 2003;48:1686-92.

47. Huusko R, Hirvonen J. The problem of determining the manner of death as suicide or accident in borderline cases. Z Rechtsmed 1988;100:207-13.

48. Gunnell D, Ashby D. Antidepressants and suicide: what is the balance of benefit and harm. BMJ 2004;329:34-8.

49. Davey Smith G, Hart C, Hole D, MacKinnon P, Gillis C, Watt G, et al. Education and occupational social class: which is the more important indicator of mortality risk? J Epidemiol Community Health 1998;52:153-60.

50. Alter DA, Naylor CD, Austin P, Tu JV. Effects of socioeconomic status on access to invasive cardiac procedures and on mortality after acute myocardial infarction. N Engl J Med 1999;341:1359-67. 